\title{
Memórias e Paisagem da Zona Portuária da Cidade do Rio Grande/RS: concepções e perspectivas de um grupo de estudantes
}

\author{
Memories and Landscape of the Rio Grande City Port Zone / RS: \\ conceptions and perspectives of a group of students
}

\author{
Memorias y paisaje de la zona portuaria de la ciudad de Río Grande / RS: \\ concepciones y perspectivas de un grupo de estudiantes
}

\author{
Maqueni Barreto Pureza ${ }^{1}$ \\ Rita de Cássia Grecco do Santos ${ }^{2}$
}

\begin{abstract}
Resumo
Este artigo tem sua origem em nossas inquietações e indagações sobre questões que transcendem aspectos puramente objetivos da existência humana. Nesse sentido, o que nos entusiasma são os entrelaçamentos entre Memória e Paisagem no contexto do Ensino de História. Por esses caminhos, a pesquisa que suscitou essa publicação aconteceu a partir dos referenciais da Nova História Cultural. Logo, consideramos as dimensões dos significados, das práticas, das representações e dos símbolos. Por esse ângulo, a questão que nos mobilizou foi a seguinte: Quais concepções e perspectivas históricas emergem entre estudantes do Ensino Fundamental, a partir do contato com a Paisagem e as Memórias da zona portuária da cidade do Rio Grande/RS? A pesquisa desenvolvida é de cunho social e articula dimensões coletivas e individuais. Para a análise das informações discursivas, utilizamos a técnica do Discurso do sujeito Coletivo (DSC), elaborada por Lefèvre e Lefèvre. Pela tessitura realizada, entendemos que emergiu uma expectativa por parte dos estudantes de que a História pudesse lhes entregar algumas "chaves" que lhes permitissem compreender sua existência no tempo e no espaço e que lhes possibilitasse a autonomia necessária para acolher ou refutar àquilo que no contexto de uma cultura é considerado essencial. Desse modo, compreendemos que as interações entre Memória e Paisagem suscitam reflexões sobre a dimensão cultural e essa condição age diretamente na ampliação da capacidade reflexiva que busca suprir demandas essenciais ao construto do ser.
\end{abstract}

Palavras-Chave: Memória; Paisagem; Ensino de História.

\begin{abstract}
This article stems from our concerns and inquiries about issues that transcend purely objective aspects of human existence. In this sense, what excites us is the intertwining between Memory and Landscape in the context of History Teaching. Along these lines, the research that prompted this publication came from the frameworks of the New Cultural History. Therefore, we consider the dimensions of meanings, practices, representations and symbols. From this angle, the question that mobilized us was: What historical conceptions and perspectives emerge among elementary school students, from the contact with the landscape and the memories of the port area of Rio Grande / RS? The research developed is of social nature and articulates collective and individual dimensions. For the analysis of discursive information, we used the technique of Collective Subject Discourse (CSD), elaborated by Lefèvre and Lefèvre. From the accomplished texture, we understand that there was an expectation on the part of the students that History could give them some "keys" that would allow them to understand their existence in time and space and to allow them the autonomy necessary to accept or refute what in the context. of a culture is considered essential. Thus, we understand that the interactions between Memory
\end{abstract}

\footnotetext{
${ }^{1}$ Mestre em História; Universidade Federal do Rio Grande - FURG, Rio Grande, Rio Grande do Sul, Brasil; furggeo@gmail.com

${ }^{2}$ Doutora em Educação; Universidade Federal do Rio Grande - FURG, Rio Grande, Rio Grande do Sul, Brasil; ritagrecco@yahoo.com.br
} 
and Landscape raise reflections on the cultural dimension and this condition acts directly on the expansion of the reflexive capacity that seeks to supply essential demands to the construct of being.

Keywords: Memory, Landscape, History Teaching.

\section{Resumen}

Este artículo se deriva de nuestras inquietudes y consultas sobre temas que trascienden aspectos puramente objetivos de la existencia humana. En este sentido, lo que nos emociona es el entrelazamiento entre Memoria y Paisaje en el contexto de la Enseñanza de la Historia. En este sentido, la investigación que impulsó esta publicación provino de los marcos de la Nueva Historia Cultural. Por lo tanto, consideramos las dimensiones de los significados, prácticas, representaciones y símbolos. Desde este ángulo, la pregunta que nos movilizó fue: ¿Qué concepciones y perspectivas históricas surgen entre los estudiantes de primaria, del contacto con el paisaje y los recuerdos de la zona portuaria de Rio Grande / RS? La investigación desarrollada es de naturaleza social y articula dimensiones colectivas e individuales. Para el análisis de la información discursiva, utilizamos la técnica del Discurso del sujeto colectivo (CSD), desarrollado por Lefèvre y Lefèvre. A partir de las texturas realizadas, entendemos que surgió la expectativa de los estudiantes de que la Historia podría darles algunas "claves" que les permitirían comprender su existencia en el tiempo y el espacio y les permitirían la autonomía necesaria para aceptar o refutar lo que en contexto. de una cultura se considera esencial. Por lo tanto, entendemos que las interacciones entre la Memoria y el Paisaje generan reflexiones sobre la dimensión cultural y esta condición actúa directamente sobre la expansión de la capacidad reflexiva que busca satisfacer las demandas esenciales de la construcción del ser.

Palabras claves: Memoria; Paisaje; Enseñanza de Historia.

\section{Introdução}

A relação da humanidade com o meio está imersa em um universo de experiências e vivências. Nessa perspectiva, sentimentos e afeições se entrelaçam numa dinâmica que permanentemente atribui sentidos à vida. Portanto, é preciso lembrar de que não são apenas os aspectos puramente objetivos e materiais que importam. Na verdade, existe um amálgama de subjetividades que conduzem nossa relação cotidiana com o espaço. Por esses caminhos, nossas indagações, inquietudes e curiosidades estão ligadas às percepções espaciais e suas implicações na maneira de interpretar o mundo.

O espaço não possui apenas elementos estéticos e utilitários. Mas contém em si aspectos intangíveis, e esses são atribuídos a partir da interiorização de ideias. Ou seja, a partir do resultado de uma soma de experiências vivenciadas por cada indivíduo. Esse complexo conjunto de significados é o palco cotidiano onde a vida acontece.

Ao considerarmos que a Paisagem é um conjunto de formas e um acúmulo de tempos (SANTOS, 1988), entendemos que nela estão contidas expressões de um paradigma. Nesse contexto, ela representa a informação acessada pelos sentidos e interiorizada serenamente, que forja modelos de interpretações quase incapazes de duvidarem da legitimidade de uma ordem. Logo, a Paisagem constitui um sistema simbólico que expressa relações de poder. De acordo com Santos: 
A dimensão da paisagem é a dimensão da percepção, o que chega aos sentidos. Por isso, o aparelho cognitivo tem importância crucial nessa apreensão, pelo fato de que toda a nossa educação, formal ou informal, é feita de forma seletiva, pessoas diferentes apresentam diversas versões do mesmo fato (1988, p. 62).

Portanto, pensamos que evidenciar memórias implícitas no contexto da formação da Paisagem significa reagir às pretensões de um discurso predominante. Generalizações não fazem parte de nosso propósito. No entanto, compreendemos que reflexões dessa natureza contribuem para encorpar a resistência a discursos oficiais.

A Paisagem contribui para a definição inconsciente de ideias, funciona como um horizonte de referência, a necessidade de entendê-la como conjunto de instrumentos simbólicos (BOURDIEU, 2003) abre a possibilidade de descortinar estruturas historicamente estabelecidas e compactuadas pacificamente. Por essa perspectiva, entendemos que trazer à tona memórias silenciadas por construções históricas, que notavelmente privilegiam uma estrutura dominante, estabelece um contraponto necessário. Dessa maneira, abrem-se espaços para o diálogo que oxigena a História e questiona verdades impérvias.

Aproximando nossas ideias ao campo em que desenvolvemos nossa pesquisa, suspeitamos que em muitos casos a Educação Básica ainda constitui a única via de acesso ao conhecimento científico para boa parte da sociedade. Nesse contexto, acreditamos que o Ensino de História tem, entre outros, um importante papel a cumprir, o de possibilitar a reflexão sobre a autenticidade de sistemas ideológicos. Isso, sem dúvida, envolve aumento da capacidade argumentativa a partir da crítica que, por sua vez, desacomoda ideias.

Assim sendo, acreditando que o Ensino de História se constitui em um campo propício para o germe da renovação de um pensamento histórico contrário às arcaicas racionalidades, seguimos em direção às nossas perspectivas. Entretanto, em momento algum pretendemos homogeneizar consciências. Ao contrário, consideramos frutíferos os espaços de diálogo despidos de assimetrias.

As ligações entre Paisagem e Memória nos interessam pelo fato de considerarmos que as composições mentais dos indivíduos numa sociedade são resultados de seleções subjetivas de informações que emanam do multifacetado universo de símbolos presentes nos espaços. Para Eliade:

A mais pálida das existências está repleta de símbolos, o homem mais "realista" vive de imagens. Repetindo, e conforme ficará abundantemente ilustrado pelo que segue, os símbolos jamais desaparecem da atualidade psíquica: eles podem mudar de aspecto; sua função permanece a mesma. Temos apenas que levantar suas novas máscaras (2002. p. 12-13, grifo nosso). 
Nesse direcionamento, Paisagem e Memória estão diretamente relacionadas às concepções históricas, ou seja, as perspectivas de História não estão apenas ligadas a Escola, em boa medida sim é verdade. Porém, partimos da ideia de que a Paisagem informa, delimita, justifica, organiza e representa modelos mentais. Isso incide diretamente na maneira que as pessoas lêem o mundo.

A partir do exposto, vale salientar que nos interessamos aqui por paisagens que fazem parte do cotidiano vivido, justamente pelo fato de que elas são repletas de memórias e significados. Fazem parte do imaginário, são testemunhas silenciosas de trajetórias de vidas e contém a face, muitas vezes, encoberta dos fatos.

A ligação da cidade do Rio Grande - RS com as águas é evidente, ambientes lacunares, estuarinos e oceânicos, historicamente fazem parte da formação desse território. Da mesma forma, as condições geográficas conferiram uma indiscutível aptidão para a implantação e desenvolvimento de atividades econômicas ligadas ao mar nessa cidade.

Não há como desvincular a cidade do Rio Grande das atividades marítimas. A essência da formação histórica dessa cidade está intrinsecamente ligada a um Porto. Seria impossível compreender Rio Grande sem imaginar que as águas que margeiam este território, desde o século XVIII testemunham o protagonismo de pescadores, negros (as) escravizados (as), comerciantes, imigrantes, colonos, militares, viajantes entre outros (as). É preciso pensar que as pedras gastas, os ferros emugrecidos, as madeiras apodrecidas, e suas cores esmaecidas são resiliências espaciais que pleiteiam com o tempo.

Nessa dinâmica, os habitantes desse lugar vão sendo construídos subjetivamente pelas brisas, os cheiros, os sabores, as texturas, os sons e as cores. Num limiar tênue entre o real e o imaginário, memórias são evocadas permanentemente e seguem forjando concepções sobre o espaço vivido. Nessa perspectiva, os vínculos da humanidade com o meio remontam aos primórdios da sua espécie. Portanto, entendemos a conveniência de percorrer as ligações inerentes entre Memória e Paisagem no âmbito do Ensino de História.

Seguindo por esses caminhos, entendemos que o mosaico de temporalidades contido nos espaços suplanta a objetividade de explicações sistemáticas. Ao passo que, emergem conjuntos de significações capazes de constituir verdades. Portanto, a questão que nos incita é a seguinte: Quais concepções e perspectivas históricas emergem entre estudantes do Ensino Fundamental, a partir do contato com a Paisagem e as Memórias da zona portuária da cidade do Rio Grande/RS? 
Precisamos esclarecer que, conforme já vínhamos sinalizando, o que nos interessa são alguns aspectos da realidade humana impossíveis de serem quantificados. Portanto, essa pesquisa se vincula uma perspectiva teórico-metodológica delineada pela pesquisa qualitativa. Pois, afinal:

A pesquisa qualitativa trabalha com o universo de significados, motivos, aspirações, crenças, valores e atitudes, o que corresponde a um espaço mais profundo das relações, dos processos e dos fenômenos que não podem ser reduzidos à operacionalização de variáveis (MINAYO, 2001, p. 21).

Nessa direção, a pesquisa desenvolvida é de caráter social (MINAYO, 2001). E, ao dialogar com o universo das representações (HALL, 2006), articula dimensões coletivas e individuais e explora as subjetividades que estão para além dos sistemas de ações e de objetos (SANTOS, 2006). Nessa perspectiva, entendemos que a força do poder simbólico (BOURDIEU, 2003) e sua capacidade de conformar mentalidades (MATOS, 2010) produzem concepções históricas (BURKE, 2008).

A ideia de poder simbólico, concebida por Bourdieu, envolve aspectos bastante abrangentes em relação aos sistemas de dominação e por isso consideramos uma referência central dessa pesquisa. Desse modo, pensamos na importância de situar nossa perspectiva para estabelecer as anteparas necessárias. Pois bem, Bourdieu defende a existência do poder, mediante o qual, as classes ou campos dominantes são beneficiários de um capital simbólico, disseminado e reproduzido por meio de instituições e práticas sociais, que lhes possibilita exercer domínio. Para o autor, esses símbolos são instrumentos que tornam possível a obtenção de um consenso acerca do sentido do mundo social e são fundamentais para a reprodução da ordem social dominante. Logo, o poder simbólico consiste "nesse poder invisível que só pode ser exercido com a cumplicidade daqueles que não querem saber que lhe estão sujeitos ou mesmo que o exercem" (BOURDIEU, 2001, p. 7-8).

Nessa acepção, poder simbólico serve para construção de uma realidade que tende a estabelecer um sentido imediato ao mundo. Ou seja, uma ideia homogênea do tempo e do espaço, tornando possível uma concordância entre os diferentes atores sociais. Portanto, estruturas tais como a língua, a cultura, o discurso ou os comportamentos, funcionam como intermediários construídos para explicar a relação com o espaço vivido atribuindo-lhe sentido. É justamente nesse seguimento que avistamos uma profícua conexão entre a Paisagem, a Memória e o Ensino de História. Ora, se a Paisagem pode ser entendida como um mosaico de temporalidades e se ela é constituída por elementos culturais que se configuram como símbolos que, em boa medida, são impressos na Memória. É razoável pensar que as 
perspectivas espaço-temporais dos alunos no contexto do Ensino de História são interiorizadas de maneira silenciosa e invisível conforme afirma Bourdieu (2001).

À vista disso, consideramos que esta pesquisa abarca uma metodologia qualitativa que permite compreender o pensamento coletivo acerca de sentidos e significados que integram intangibilidades. Para tanto, temos entendido que metodologias qualitativas são,

aquelas capazes de incorporar a questão do significado e da intencionalidade como inerentes aos atos, às relações, e às estruturas sociais, sendo essas últimas tomadas tanto no seu advento quanto na sua transformação, como construções humanas significativas (MINAYO, 2006, p. 22-23).

Assim, partimos do princípio de que a pesquisa qualitativa lida com informações produzidas pelo pesquisador cuja essência não se deixa traduzir por números. Sendo assim, nesse caso a via mais fecunda se relaciona com a análise de textos falados ou escritos bem como a observação direta do comportamento. Dessa forma, conforme Moraes e Galiazzi entendemos que a pesquisa qualitativa,

pretende aprofundar a compreensão dos fenômenos que investiga a partir da uma análise rigorosa e criteriosa desse tipo de informação. Não pretende testar hipóteses para comprová-las ou refutá-las ao final da pesquisa: a intenção é a compreensão, reconstruir conhecimentos existentes sobre os temas investigados (2007, p.11).

Logo, por meio da pesquisa qualitativa pretendemos aprofundar nossas percepções acerca do fenômeno investigado, refinando o olhar na busca de um processo flexível e dinâmico. Além do mais, na medida em que, enquanto pesquisadores, nosso interesse esteve ligado à dimensão simbólica, estamos bastante convencidos que,

todo discurso individual representa um discurso socialmente compartilhado. Em resumo, é sempre um discurso socialmente implicado, pois seu sentido está atrelado aos contextos sociais de produção. Mesmo que sejam poucas pessoas a formularem seus discursos, elas emitem um discurso que não representa somente um ponto de vista pessoal, pois a sua subjetividade é construída no contexto social (GONDIM; FISCHER, 2009, p.17).

Nesse enquadramento, os indivíduos podem ser considerados, em certa medida, verdadeiros microcosmos que contêm em si a essência de grandes paradigmas. Longe de pretender análises generalistas e/ou simplificadoras, o que nos intriga é a potência dos simbolismos e sua capacidade peristáltica de modelar mentalidades à revelia das consciências. De todo modo, precisamos deixar claro que não tivemos o intuito de testar posicionamentos previamente estabelecidos como possíveis hipóteses. Assim sendo, entendemos que, 
aquilo que os investigadores qualitativos tentam fazer é estudar objetivamente os estados subjetivos dos sujeitos. Ainda que a ideia que os investigadores sejam capazes de ultrapassar alguns de seus enviesamentos possa, inicialmente, ser difícil de aceitar, os métodos que eles utilizam auxiliam nesse processo (BOGDAN; BIKLEN, 1994, p. 67).

Consideramos que a constituição de pensamentos e condutas dos indivíduos em determinada sociedade reflete grandes paradigmas historicamente estabelecidos, nessa afirmação residem os alcances da teoria da representação social, esta pode ser entendida como uma preparação para a ação, pois é capaz de conduzir o comportamento (MOSCOVICI, 1978).

Nesse enquadramento, acreditamos que o discurso do grupo de indivíduos participantes desta pesquisa nos forneceu relevantes indicações sobre a questão que mobiliza este estudo. No entanto, estamos cientes de que os resultados desta pesquisa, em hipótese alguma, pretendem constituir pretextos para generalizações e/ou anacronismos.

\section{Caminhos metodológicos}

Para melhor compreensão de nossos (as) leitores (as), as informações analisadas foram produzidas a partir de um coletivo composto por estudantes da Rede Pública Estadual de Ensino, mais especificamente por 18 alunos do oitavo ano do Ensino Fundamental do Instituto Estadual de Educação Juvenal Miller, que está localizado no centro da cidade do Rio Grande/RS. Na trilha de nossas estratégias metodológicas, num primeiro momento apresentamos, aos sujeitos da pesquisa, relatos de cronistas estrangeiros que no início do século XIX estiveram neste território que hoje conhecemos como cidade do Rio Grande. Nessa perspectiva, a contribuição desses viajantes pode representar subsídios significativos para reconstruções históricas, além de ampliar as percepções acerca da dimensão simbólica que, por sua vez, estabelece contornos às noções históricas. Para Alves:

Verdades inquestionáveis ou asserções esquecidas debaixo dos tapetes da historiografia - estes têm sido, normalmente, os destinos dados aos relatos de cronistas estrangeiros que fizeram referências às terras e à gente sul rio-grandense, desde tempos remotos até outros mais contemporâneos. Ainda que pinçadas e realçadas ou mesmo que esquecidas propositalmente em alguns de seus detalhes pelos historiadores, as narrativas dos viajantes/estudiosos estrangeiros passaram, já a muito tempo, a constituir verdadeira pedra de toque da produção historiográfica (2007, p. 20).

Nesse sentido, os relatos dos cronistas estrangeiros emanam memórias e representam uma perspectiva distinta em relação a uma concepção mais tradicional de história. Assim sendo, selecionamos fragmentos que tratam mais especificamente da Paisagem portuária da 
cidade do Rio Grande. Para tanto, trabalhamos com alguns escritos de Luccock, Saint-Hilaire, Dreys, Seidler, Isabelle, Baguet, Hörmeyer e Avé-Lallemant.

Com o intuito de mobilizar a produção de informações discursivas, logo após a apresentação dos extratos textuais, num segundo momento, realizamos uma amostra fotográfica. Nessa perspectiva trabalhamos com parte do acervo fotográfico gentilmente cedido pela diretoria do Museu do Porto da cidade do Rio Grande. As fotografias selecionadas para esta etapa da pesquisa estão relacionadas com alguns aspectos da Paisagem portuária capazes de fazer refletir sobre as origens, quase imperceptíveis, de concepções históricas arraigadas coletivamente pelo poder simbólico (BOURDIEU, 2003).

Nessa fase, pensamos na fertilidade do uso de imagens como uma potente linguagem capaz de expressar uma grande quantidade de ideias. Além do mais, as interpretações que irão se originar estão diretamente ligadas às singularidades subjetivas. Nesse caso, os discursos emanados podem revelar a tônica das mentalidades. Dessa forma, o raio de ação da metodologia se amplia, uma vez que;

A contribuição mais importante que a fotografia pode trazer à pesquisa e ao discurso em ciências sociais reside no fato de que, pela sua própria natureza, ela abre as vias para uma percepção do mundo visível diferente daquela propiciada por outros métodos de investigação (GURAN, 2011, p. 86).

No entanto, estivemos atentos às especificidades do uso de fotografias como parte dos procedimentos aplicados na produção de informações, afinal:

Para que uma fotografia cumpra suas funções na pesquisa, é necessário que ela seja eficiente na tarefa de recolher e transmitir informações: uma fotografia malfeita é como um texto mal escrito, cujo sentido escapa ao leitor. A utilização da fotografia se dá através da leitura da imagem, isto é, do reconhecimento das informações nela contidas, as quais propiciam uma reflexão científica. Por sua vez, ela será tão mais rica em informação quanto for a capacidade do leitor de perceber as suas nuances de representação (GURAN, 2011, p. 89).

Após os sujeitos da pesquisa estarem em contato com as fotografias selecionadas, num terceiro momento realizamos uma saída de campo, nesta ocasião estivemos percorrendo uma região situada no centro histórico da cidade do Rio Grande conhecida como Porto Velho. Nesse momento, os (as) estudantes entraram em contato direto com a Paisagem portuária. Ainda nessa oportunidade visitamos o Museu do Porto, consideramos que esse lugar de memórias contribuiu para estruturar de significações indispensáveis na construção de percepções espaço-temporais. 
Direcionando as ações empíricas, no intuito de mobilizar a produção de informações discursivas, convidamos cada um dos estudantes a confeccionar uma carta direcionada a possíveis futuros visitantes do Museu do Porto. Além disso, propomos a criação de um grupo de conversações no aplicativo multiplataforma de mensagens instantâneas chamado WhatsApp. Nessa direção, posteriormente levantamos questões norteadoras capazes de criar um espaço de diálogo em torno de nosso objeto de pesquisa. Objetivamos com isso, a partir das narrativas escritas, mobilizadas em ambas estratégias, alcançar os subsídios discursivos que foram a base para a construção do discurso coletivizado.

Pelo fato de almejarmos acessar dimensões subjetivas intrínsecas e próprias da existência humana e em virtude de estarmos buscando compreender quais as concepções e as perspectivas históricas emergem entre estudantes do Ensino Fundamental, a partir do contato com a Paisagem e as Memórias da zona portuária da cidade do Rio Grande/RS, utilizamos como técnica de análise a proposta do Discurso do Sujeito Coletivo (DSC) elaborada por Lefèvre e Lefèvre (2005). Essa técnica trata da “[...] organização e tabulação de dados qualitativos de natureza verbal, obtidos de depoimentos, artigos de jornal, matérias de revistas semanais, cartas, papers, revistas especializadas, etc" (LEFÈVRE; LEFÈVRE, 2005, p.16).

A escolha pelo DSC se deu em decorrência ao nosso anseio em analisar a discursividade de um coletivo, de forma a integrar os pensamentos individuais em uma única fala que expresse ideias acerca de determinada temática. Para isso, consideramos que o pensamento, tanto individual quanto coletivo, não se comporta da mesma maneira que atributos ou variáveis utilizadas em pesquisas quantitativas. Assim, em conformidade com Lefèvre e Lefèvre assumimos a ideia de que;

O pensamento coletivo precisa sempre ser pesquisado qualitativamente, justamente por que ele é uma variável qualitativa que, ao contrário de variáveis quantitativas como peso, altura, renda, etc., não é pré, mas pós-construída, isto é, não se configura como um input, mas como output da pesquisa $(2005$, p.10).

Diante disso, buscamos preservar a discursividade, desde a elaboração das questões, passando pela produção das informações e pela sua análise, até o momento da apresentação dos resultados. Dessa forma, procuramos considerar a característica, especificamente qualitativa, do pensamento coletivo.

Nesse viés, Lefèvre e Lefèvre (2005, p.14) afirmam que o fato das coletividades terem “ideias, opiniões, crenças e também peso, altura não quer dizer que se possa investigar científica e sistematicamente, os pensamentos, da mesma forma que investigamos atributos 
como peso e altura". Nesse sentido, os autores trazem em seu livro "O discurso do sujeito coletivo: Um novo enfoque em pesquisa qualitativa (Desdobramentos)" a ideia do ter e do professar, o que para eles são coisas distintas.

Nesse contexto, quando pesquisamos algo que as pessoas já “têm”, não podemos construir nada mais além. No entanto, quando direcionamos a pesquisa ao que as pessoas "professam" temos a possibilidade de reconstruir um discurso durante o próprio processo de investigação, o que segundo Lefèvre e Lefèvre:

Quer dizer que se estará descrevendo muito melhor e muito mais adequadamente os pensamentos de indivíduos e coletividades quando esses estiverem sendo coletados, processados e apresentados sob a forma de discurso, por que os pensamentos pertencem à família das línguas e linguagens e, portanto, à ordem do discurso ou do texto $(2005$, p.14).

Para tornar os discursos individuais em discursos coletivos acreditamos ser possível a produção da soma desses discursos. Segundo Lefèvre e Lefèvre, esses discursos,

Não se anulam ou se reduzem a uma categoria comum unificadora já que o que se busca fazer é reconstruir, com pedaços de discursos individuais, como um quebracabeça, tantos discursos-síntese quantos se julgue necessários para expressar uma dada "figura", ou seja, um dado pensar ou representação social sobre um fenômeno (2005, p. 19).

Dessa forma, para auxiliar o pesquisador na organização das informações discursivas, Lefèvre e Lefèvre (2005) elaboraram quatro figuras metodológicas denominadas: ExpressõesChave (ECH), Ideias Centrais (IC), Ancoragem (AC) e Discurso do Sujeito Coletivo (DSC). As ECH representam os trechos das respostas obtidas de depoimentos e/ou de questionários que são mais significativas, ou seja, que revelam a essência dos discursos individuais. Essas expressões dão corpo ao DSC, que é o discurso síntese e que se apresenta na primeira pessoa do singular. Nesse discurso, estão imbricadas as IC que revelam o sentido das expressõeschave de maneira mais precisa possível.

Algumas ECH remetem a determinadas teorias, crenças, ideologias, manifestadas nas respostas e percebidas pelo pesquisador ao analisar as informações. A essas expressões denominamos Ancoragens (AC) e estão presente na maioria dos discursos. No entanto, para determinarmos uma AC é necessário evidenciar nos discursos individuais marcas linguísticas explicitas que as referenciam (LEFÈVRE; LEFÈVRE, 2005). Portanto, no decorrer do processo de aplicação da técnica de análise, os movimentos convergem para originar o discurso coletivo. Seguindo por esses caminhos, teremos um conjunto de ideias que representam paradigmas mentais historicamente estabelecidos. 
A partir de então, num primeiro momento, organizamos o material discursivo em uma tabela denominada: Primeiro Instrumento de Análise do Discurso A - IAD $\mathrm{IA}_{1 \mathrm{~A}}$ Nessa tabela, identificamos as Expressões-Chave - ECH e suas respectivas Ideias Centrais - IC e Ancoragens - AC. Partindo desse subsídio discursivo, identificamos as Expressões-Chave. Posteriormente, a partir de cores distintas associamos as Ideias Centrais às respectivas Expressões-Chave. Feito isso, por meio de um movimento de releitura identificamos as Ancoragens. Então, seguimos para a construção do Segundo Instrumento de Análise do Discurso. Com base nas operacionalizações, no contexto da técnica de análise do Discurso de Sujeito Coletivo - DSC realizadas até então foi possível produzir uma peça discursiva a qual denominamos de acordo com sua essência.

\section{Desdobramentos da Pesquisa}

Logo no início do discurso, percebemos na fala coletiva que o estudante do $8^{\circ}$ ano do Ensino Fundamental de fato se preocupa em conhecer os acontecimentos que estão na gênese da constituição da cidade do Rio Grande. Por detrás da simplicidade e da objetividade da linguagem escrita presente nas primeiras linhas desse discurso, há uma inquietação que anseia situar-se no tempo e no espaço. Nessa perspectiva, seria interessante trazer a tona a ideia expressa por Halbwachs de que, ao examinar seu passado, determinado grupo social percebe a possibilidade de adquirir "consciência de sua identidade através do tempo" (HALBWACHS, 2006, p.109).

Portanto, estar hoje em determinado espaço em determinado tempo parece que demanda referênciais, é preciso saber o que havia para compreender o que há. Porém, quando não existe Memória do que foi, o hiato chega a ser perturbador. Isso em função de que somos seres culturais e a existência da espécie humana está diretamente ligada à transmissão de cultura e não à dimensão instintiva e tão somente biológica. Para Laraia: "O modo de ver o mundo, as apreciações de ordem moral e valorativa, os diferentes comportamentos sociais e mesmo as posturas corporais são assim produtos de uma herança cultural, ou seja, o resultado da operação de uma determinada cultura (2009, p. 67)". Assim, evidencia-se a força que o simbolismo da Paisagem exerce nessa busca por situar-se. Afinal, a leitura sensorial que se faz da Paisagem vai forjando concepções de mundo, segundo Costa:

O símbolo presente na paisagem pode também ser definido como um elemento mediador entre os diferentes registros da experiência e a comunicação humana. A experiência e a comunicação humana tem uma dimensão irredutivelmente espacial: o mundo conhecido e imaginado que a atividade humana convertem em um 
complexo de significados, manifestos em uma realidade geográfica que são [...] suportes privilegiados do processo de simbolização, da conversão em símbolos dos elementos concretos presentes no cotidiano (2008, p. 151).

Nessa direção, surge uma possível via de acesso para tomar a Paisagem como possibilidade a ser explorada no contexto do Ensino de História.

Na sequência do discurso, observamos uma menção sobre valorizar a própria história, esse fato pode estar ligado a uma busca por identidade ou mesmo a uma procura por elementos para justificar a importância de se existir no "hoje" ou ainda, um anseio por encontrar parâmetros espaço-temporais que orientem a mentalidade na busca por conexões entre o individual e o coletivo, o longo tempo e o cotidiano, o inconsciente e o intencional (LE GOFF, 1976).

Além disso, encontramos um trecho que nos remete a ideia de conhecer histórias para fazer justiça a partir disso. Nessa direção, o sujeito relata que: “devíamos dar mais valor para nossa história. Afinal, no passado as pessoas trabalharam muito nessa cidade e deram a sua vida para beneficiar muita gente ( $\left.\operatorname{DSC}_{1}\right)$ ". Esse viés do discurso nos leva a pensar que existe a presença de uma espécie de consciência de classe, que ainda inspira certo senso crítico em relação a uma face mais elitizada da história. Para Fenelon:

A História faz sentido como fonte de inspiração e de compreensão, não apenas porque pode fornecer os meios de inter relação com o passado, mas também porque nos permite elaborar o ponto de vista crítico através do qual se pode ver o presente (2009, p. 33).

Por outro lado, verificamos que no contexto do discurso em pauta também aflora determinado orgulho: "Esse é um lugar com muitas histórias. Fiquei sabendo que vários navios encalhavam e naufragavam quando não existiam aquelas pedras nos Molhes da Barra, pois os fortes ventos dificultavam a vida dos tripulantes das embarcações (DSC 1 )". Esse fragmento, em algum momento nos chama a atenção pelo fato do sujeito fazer questão de afirmar que a cidade do Rio Grande é um lugar com muitas histórias. Contudo, bem sabemos que todos os lugares contêm várias histórias e o que vai determinar o quão importantes elas se constituem é justamente a ligação afetiva que os seus habitantes tem com esses lugares.

Além disso, muitas dessas histórias, só serão importantes para àqueles que lhe atribuem significados intangíveis que flertam com a dimensão do mítico. Porém, frequentemente apenas atingem o status de lendas. No entanto, esse trecho também nos remete a noção de busca de identidade e pertencimento. Uma vez que, o sujeito ao afirmar 
que estava se referindo a um lugar com muitas histórias, dá a ideia de considerar elas importantes e apresenta um pequeno trecho de um possível acontecimento como forma de provar que de fato fala de algo relevante. À vista disso, “[...] no fundo, é a identidade que está na origem da memória. Nós não somos a soma de nossas recordações, mas aquilo que somos determina o conjunto de nossas recordações” (TEDESCO, 2004, p.94).

No decorrer do discurso, verificamos uma espécie de julgamento: "as pessoas por aqui não dão a mínima para a história que têm”. Fica evidente que o sujeito está convencido de que existe uma desvalorização da história. E nessa lógica, constatamos que está se considerando que existe uma história e que ela precisa ser valorizada. Nesse segmento, segundo o sujeito coletivo, quem deveria dar o devido valor para a história seria a população riograndina. Pois bem, os questionamentos que nos sobrevém são: Dar valor a que? Dar valor por quê? Dar valor de que maneira? Para responder a essas questões recorremos a outro trecho do discurso em questão:

Existem tantas coisas antigas e interessantes que se torna até importante saber o que ocorre e o que ocorreu no Rio Grande. Enfim, eu acho que deve ser sempre assim, ir guardando as coisas legais e importantes para um dia as crianças estejam fazendo a mesma coisa que nós fizemos, olhar como as coisas aconteciam no tempo passado e fazer tudo reviver $\left(\mathrm{DSC}_{1}\right)$.

Fica evidenciado que o sujeito associa história à dimensão material. Nesse caso, coisas antigas e interessantes (objetos, artefatos, edificações etc.). Além disso, apesar das fragilidades da escrita, o sujeito julga importante valorizar a história para saber o que aconteceu e entender o que acontece e arremata o trecho nos dando a idéia de história cíclica.

Seguindo o discurso, o sujeito afirma que: “[...] a história do Porto é muito mais interessante do que eu achava. As histórias sobre o Porto são legais, um pouco mentirosas, mas legais $\left(\mathrm{DSC}_{1}\right)$ ". Essa colocação nos leva a pensar que gostar da história não significa necessariamente acreditar nela. De fato a conotação de caricatura atribuída pela tentativa de inflar histórias para reafirmarem identidades ou forjá-las, trazem o risco de causar um efeito colateral. Ou seja, existe o perigo de fazer com que a História para a escola seja vista pelos estudantes como uma fábula ou conto.

Sabemos que no contexto do Ensino de História, a curiosidade é capaz de mobilizar aprendizagens. Afinal, é em consequência dela que os (as) estudantes vão se transformando com suas ideias em reais sujeitos da construção e reconstrução do conhecimento (PATRÍCIO; MATOS, 2011). Suspeitamos que essa realidade tenha sido delineada quando o sujeito afirma: "gosto de observar os textos escritos pelos navegantes que estiveram por aqui no 
passado, pois eles explicavam sobre tudo o que acontecia com eles e isso desperta muita curiosidade $\left(\mathrm{DSC}_{1}\right)$ ". Nesse segmento, pensamos que associar o Ensino de História com imagens, artefatos, documentos e etc. seja uma rica possibilidade para as aprendizagens.

Quando observamos de que maneira a Paisagem está transfigurada nas entrelinhas do discurso coletivizado, percebemos que o determinismo geográfico é um fator relevante para a constituição dos modos de vida, dos valores, da cultura de forma geral. Por essas veredas, a Paisagem tem sim a capacidade de informar. Ou seja, é o que chega pelos sentidos que é processado na dimensão subjetiva e não ao contrário.

Segundo o sujeito coletivo: "A cidade do Rio Grande é de ventos fortes e de uma aparência chata. Se não fosse pelo Porto, a vida por aqui seria difícil ( $\left.\mathrm{DSC}_{1}\right)$ ). Notemos que nessa afirmativa, é uma condição climática e paisagística que leva à conclusão de que a vida poderia ser difícil. Contudo, o sujeito atribui ao Porto, uma interferência humana na paisagem, a qualidade de ser o responsável pela viabilidade de uma vida menos dura. O que fica evidente é a noção de que é necessário subverter a natureza e transformar a Paisagem para que seja possível um processo civilizatório. Nessa dinâmica, a História é a história das realizações, das proezas dos grandes feitos da humanidade.

Pelo fato de nos interessarmos pela dimensão subjetiva e intangível da existência humana, em determinado momento dos processos de produção de informações emergiram narrativas que estavam desprendidas das materialidades objetivas. Afinal:

O caráter simbólico dos lugares revela-se ao ser humano como algo que precede a linguagem e a razão discursiva, apresentando assim determinados aspectos do real, enfatizando as relações entre o simbólico e o lugar. Estas relações são mediatizadas pelos símbolos que podem ser uma realidade material e que une-se a uma idéia, um valor, um sentimento (COSTA, 2008, p. 149).

Portanto, ao percebermos uma possibilidade vinculada à criatividade, julgamos que seria enriquecedor fomentarmos esse processo. Dessa maneira, sobre as relações entre a Paisagem e as Memórias portuárias da cidade de Rio grande/RS, o sujeito relata:

Para encerrar faço aqui uma carta para alertar a todos os amigos que há um grande perigo nas águas próximas á cidade do Rio Grande. Elas mais parecem águas amaldiçoadas, águas que apresentam uma dificuldade enorme para se navegar, tanto pelo vento de rajadas extremamente fortes quanto por um canal muito raso. Quanto ao caminho por terra, vi um bioma muito inusitado de pântanos e areais com uma vegetação rasteira. Local ventoso com o clima bastante nublado, o mar é bem movimentado com vários barcos ancorados no porto, local muito poluído devido às descargas dos barcos e pela dragagem que já foi feita anteriormente e teve aval para ser feita novamente $\left(\mathrm{DSC}_{1}\right)$. 
Verificamos que o excerto do discurso revela uma linha tênue entre a realidade vivida e o imaginário, isso por que o sujeito inicia o trecho escrevendo sobre algo fictício. Porém, para isso apresenta suas percepções sobre a Paisagem e acessa sua Memória para retomar e relatar algumas de suas noções subjetivas. Quando o sujeito afirma que: “[...] há um grande perigo nas águas próximas á cidade do Rio Grande. Elas mais parecem águas amaldiçoadas [...] (DSC $\left.{ }_{1}\right)$ " constatamos que ao atribuir o caráter de amaldiçoadas às águas que margeiam a cidade justamente pelo suposto perigo que oferecem, a dimensão do discurso passa para questões transcendentais. Portanto, não podem mais ser explicadas racionalmente.

Contudo, em outro momento do discurso, percebemos que a narrativa paulatinamente volta para o campo da objetividade, isso pode ser constatado quando o sujeito escreve: "Local ventoso com o clima bastante nublado, o mar é bem movimentado com vários barcos ancorados no porto, local muito poluído devido às descargas dos barcos e pela dragagem que já foi feita anteriormente e teve aval para ser feita novamente $\left(\mathrm{DSC}_{1}\right)$ ). Notemos que inclusive, existe uma menção à dragagem que realmente estava sendo realizada no dia em que o coletivo de estudantes esteve em contato com a paisagem portuária. Além disso, o sujeito coletivo se refere a uma coisa que ele chamou de poluição, acreditamos que nesse momento uma possível visão romantizada possa ter sido abalada.

\section{Considerações}

Ao longo desse percurso, buscamos constituir elementos que nos permitissem compreender quais as perspectivas históricas que emergem entre estudantes do Ensino Fundamental, a partir do contato com a Paisagem e as Memórias da zona portuária da cidade do Rio Grande/RS, para contribuir no entendimento de diferentes concepções no Ensino de História. Assim, consideramos importante compartilhar que as experiências vivenciadas ao longo da construção e desenvolvimento dessa pesquisa foram transformadoras e certamente seguirão imbricadas à nossa constituição de ser professor. Portanto, essa escrita evidentemente nos levou a refletir sobre o que fazemos e sobre o que desejamos continuar fazendo em nossas práticas docentes.

Retomar as dinâmicas vividas nas redes de conversações com o coletivo de estudantes que se constituíram como sujeitos da pesquisa, nos faz pensar que todos nós fomos, em alguma medida, modificados. Afinal, essas relações foram permeadas por problematizações, negociações e emoções. Logo, compreendemos e ressignificamos princípios vislumbrando possibilidades e impossibilidades.

Pois bem, pela tessitura realizada entendemos que emergiu uma expectativa por parte 
dos estudantes de que a História pudesse lhes entregar algumas "chaves" que lhes permitissem compreender sua existência no tempo e no espaço, que lhes possibilitasse a autonomia necessária para acolher ou refutar àquilo que no contexto de uma cultura é considerado essencial. Além disso, percebemos uma ânsia por explicações que sejam capazes de preencher um vazio perturbador que se nutre de uma frágil consciência histórica.

Nesse segmento, identificamos no coletivo de estudantes uma "sede" por encontrar logo uma história que eles pudessem chamar de sua. Ou seja, grande parte das narrativas históricas ainda está muito distante, elas falam de coisas, lugares e personalidades que parecem não significar muito. Assim, em alguns casos, a sistematização de conteúdos previstos no currículo se torna apenas uma questão momentânea de memorização, sim estamos falando de decorar e transcrever.

Diante desse contexto, entendemos que a possibilidade de articular a História nas escalas local e global abre uma via que estimula a produção de significados e que por isso desloca a perspectiva do fatídico para o prazeroso. Logo, se existe um terreno fértil que nesse caso consideramos ser a busca por histórias capazes de dar acesso às compreensões espaçotemporais, e se associado a isso está à curiosidade, estamos diante de uma oportunidade de trazer para o contexto do Ensino de História as relações entre Paisagem e Memória.

Somos levados a considerar essa possibilidade pelo fato de que se a Paisagem, por tudo o que é, tem a característica de informar e delimitar os contornos das racionalidades e se a Memória em boa medida se relaciona com essas acepções, estamos num limiar entre a história que se ouve, se lê em alguns casos se estuda e a história que se sente, que faz sentido, que instrumentaliza as relações com a vida cotidiana.

Nesse enquadramento, percebemos que o contato com a Paisagem e as Memórias portuárias suscitou no grupo de estudantes uma vontade de sentir-se parte da história, esse fenômeno está ligado à busca pela construção de um sentimento de pertencimento com o lugar e só pode ser compreendido quando consideramos a dimensão subjetiva da existência humana. Além disso, verificamos que a história que mobiliza não é a dos grandes eventos e dos heróis, mas é a dos esquecidos pela historiografia que está alinhada a um viés mais ortodoxo da História oficial.

Compreendemos também que a relação entre a Paisagem a as Memórias portuárias remeteu o coletivo de estudantes a certo sentimento de melancolia. Acreditamos que isso está ligado ao fato de que o cais adjacente ao Museu, visitado por ocasião da saída de campo, é um lugar que transpira o cotidiano real, sem nenhuma máscara e longe de qualquer preocupação estética para agradar visitantes. É ali o palco onde está impressa a dureza do trabalho e a 
rispidez de uma racionalidade que prevê apenas o que é materialmente objetivo. Assim, a mensagem chega pelos sentidos se revela através do acúmulo de objetos na beira do cais, dos sons dos motores, dos cheiros e das texturas indelicadas.

Da mesma maneira, o acervo do Museu do Porto está totalmente relacionado à construção do Molhes da Barra e por isso remete à dificuldade do trabalho vivenciada por trabalhadores e trabalhadoras nesse contexto. Além disso, pensamos que as condições de tempo/clima no dia da saída de campo contribuíram para uma percepção mais umbrosa por parte dos estudantes, uma vez que nessa ocasião contamos com tempo nublado e ventoso. Por tudo isso, somos levados a considerar que as apreensões e compreensões que se tem da história são mediadas pela Paisagem percebida e pelas Memórias acessadas pelos indivíduos em suas relações com o mundo vivido.

Além disso, identificamos que as interações entre Memória e Paisagem suscitam reflexões sobre a dimensão cultural e essa condição age diretamente na ampliação da capacidade reflexiva que busca suprir demandas essenciais ao construto do ser. Logo, convergimos para a ideia de buscar estabelecer parâmetros que possibilitem apreender noções espaço-temporais e que sejam capazes de atribuir sentidos para a existência.

Ademais, esperamos que essa pesquisa represente um movimento que se soma às perspectivas que consideram, num momento crucial em que o avanço do conservadorismo ganha espaço, o Ensino de História como sendo estratégico para a manutenção da diversidade de pensamentos. Com isso, desejamos que o Ensino de História continue problematizando, desacomodando e desestabilizando o status de alguns grupos sociais no Brasil. Ensejamos que os debates nas salas de aula sejam marcados pelo pluralismo democrático, que possamos encarar as ameaças e seguir compartilhando a multiplicidade de olhares. Que a História na escola continue propondo críticas ao mundo e abrindo possibilidades de interpretações da vida.

\section{Referências}

ALVES, F. N. Porto e Barra do Rio Grande: uma secular aspiração que se tornou realidade (uma introdução ao tema), Porto Alegre: CORAG, 2007.

BOGDAN, R; BIKLEN, S. Investigação qualitativa em educação. Trad. de Maria João Alvarez, Sara Bahia dos Santos e Telmo Mourinho Baptista. Portugal: Porto Editora, 1994.

BOURDIEU, P. O poder simbólico. Trad. de Fernando Tomaz. 6ed. Rio de Janeiro: Bertrand Brasil, 2003. O poder simbólico. 4ed. Rio de Janeiro: Bertrand Brasil, 2001. 
BURKE, P. O que é história cultural? Trad. Sérgio de Goes de Paula. 2ed. Rio de Janeiro: Zahar, 2008.

COSTA, O. Memória e Paisagem: em busca do simbólico dos lugares. In: Espaço e Cultura. Rio de Janeiro, edição comemorativa, p. 149-156, 1993-2008 ISSN. 1413-3342. Disponível em: https://www.e-publicacoes.uerj.br/index.php/espacoecultura/article/view/7731. Acesso em: 26 dez. 2019.

ELIADE, M. Imagens e Símbolos: ensaio sobre o simbolismo mágico-religioso. São Paulo: Martins Fontes, 2002.

FENELON, D. O historiador e a cultura popular: história de classe ou história do povo? História \& Perspectivas, Uberlândia, v. 1, n. 40, p. 27-51, jan/jun. 2009. ISSN. 2176-4352 Disponível em: http://www.seer.ufu.br/index.php/historiaperspectivas/article/view/19207. Acesso em: 26 dez. 2019.

GONDIM, S. M. G; FISCHER, T. O discurso, a análise de discurso e a metodologia do discurso do sujeito coletivo na gestão intercultural. Cadernos Gestão Social, Salvador, v. 2, n. 1, set/dez, 2009. p. 09-26. ISSN 1982-5447. Disponível em: https://portalseer.ufba.br/index.php/cgs/article/view/31544. Acesso em: 26 dez. 2019.

GURAN, M. Considerações sobre a constituição e a utilização de um corpus fotográfico na pesquisa antropológica. Discursos Fotográficos, v. 7, n. 10, jan/jun, 2011. p. 77-106. ISSN 1984-7939.

em: http://www.uel.br/revistas/uel/index.php/discursosfotograficos/article/view/9215. Acesso em: 26 dez. 2019.

HALBWACHS, M. A Memória Coletiva. São Paulo: Centauro, 2006.

HALL, S. A identidade cultural na pós-modernidade. Trad. de Tomaz Tadeu da Silva e Guacira Lopes Louro.11ed. Rio de Janeiro: DP\&A, 2006.

LARAIA, R. Cultura: um conceito antropológico. 24 ed. Rio de Janeiro, RJ, Jorge Zahar:2009.

LE GOFF, J. (Org.) História: novos objetos. Rio de Janeiro: Francisco Alves, 1976.

LEFÈVRE, F; LEFÈVRE, A. M. C. O discurso do sujeito coletivo: um novo enfoque em pesquisa qualitativa (desdobramentos). Caxias do Sul: Educs, 2005.

MATOS, J. Tendências e debates: da escola dos annales à história nova. Historiae, Rio Grande, v. 1, n. 1, p. 113-130, 2010. ISSN 1519-8502. Disponível em: https://periodicos.furg.br/hist/article/view/2283/1183. Acesso em: 26 dez. 2019.

MINAYO, M. O desafio do conhecimento: pesquisa qualitativa em saúde. 9ed. São Paulo: Hucitec, 2006.

(org.). Pesquisa Social: Teoria, método e criatividade. 18ed. Petrópolis: Vozes, 
MORAES, R; GALIAZZI, M. Análise Textual Discursiva. Ijuí: Ed. da UNIJUÍ, 2007.

MOSCOVICI, S. A representação social da psicanálise.Traduzido por Álvaro Cabral. Rio de Janeiro: Zahar, 1978.

PATRÍCIO, N. C; MATOS, F. J. A curiosidade como produção do conhecimento discente no processo de aprendizagem. In: $2^{\circ}$ Encontro de Pesquisa e Pós-Graduação em Humanidades. $8^{a}$ Semana de Humanidades. Humanidades: entre fixos e fluxos. 2011, Ceará. Anais do $2^{\circ}$ EPGH. Ceará: Universidade Federal do Ceará/UFC, 2011.

SANTOS, M. A Natureza do Espaço: Técnica e Tempo, Razão e Emoção. 4ed. São Paulo: Editora da Universidade de São Paulo, 2006.

Metamorfose do espaço habitado. São Paulo: Hucitec, 1988.

TEDESCO, J. C. Nas Cercanias da Memória: temporalidade, experiência e narração. Passo Fundo, RS: UPF; Caxias do Sul, RS: EDUCS, 2004. 